function were more controversial and available data did not argue for a direct vascular effect of MTX in RA.

In psoriatic arthritis, evidences were more scarce. A meta-analysis showed that methotrexate was associated with a reduction of cardiovascular events in patients with psoriatic arththritis. In psoriatic arthritis, methotrexate did not improve the endothelial function.

In plaque psoriasis, available data were rare. The use of methotrexate in this condition was not associated with a reduction of cardiovascular events. Nevertheless, a decrease in circulating VCAM-1 and in E selectin levels was described with the use of methotrexate.

In HIV infection, a model of pro inflammatory state, the use of methotrexate did not change the endothelial function and thus the cardiovascular events.

Finally, in general population, the use of methotrexate did not decrease the occurrence of cardiovascular events after a myocardial infarction.

Conclusion: The cardiovascular effects of methotrexate are poorly understood at this time. Nevertheless, it seems clear that methotrexate can reduce the occurrence of cardiovascular events in inflammatory disease. The mechanisms explaining this good issue are poorly understood, but it seems possible that the essential effect of methotrexate lies in the reduction of the inflammatory syndrome without a direct vascular impact.

Disclosure of Interests: None declared

DOI: 10.1136/annrheumdis-2021-eular.2694

\section{AB0267 HOW EFFECTIVE IS PAIN MANAGEMENT IN THE PATIENTS' OPINION? DATA FROM THE COMPAS STUDY}

E. Pogozheva ${ }^{1}$, A. Karateev ${ }^{1}$, V. Amirdzhanova ${ }^{1} .{ }^{1}$ V. A. Nasonova Research Institute, Pain Management, Moscow, Russian Federation

Objectives: to evaluate the effectiveness and satisfaction of pain management in patients with rheumatic diseases (RD) according to a survey in the COMPAS (Quality of Pain Management according to Patients with Arthritis and Back pain) study.

Methods: the survey involved 1040 patients with RD (rheumatoid arthritis-40.6\%, osteoarthritis $-32.1 \%$, spondyloarthritis- $10.6 \%$, connective tissue diseases-8.6\% of patients). $76.8 \%$ were women, the mean age was $55.8 \pm 14.0$ years. $35.7 \%$ of patients continued to work in their specialty, $31.6 \%$ had various degrees of disability. The effectiveness of pain therapy was evaluated by the patient in the last month preceding the survey on a 5-point scale, where 1 - no effect and 5-excellent effect. Patients ' satisfaction with treatment, possible reasons for the lack of effectiveness of pain therapy and the use of additional treatment tools were also evaluated.

Results: as therapy for the underlying disease, $40 \%$ of patients received conventional disease modifying antirheumatic drugs, $33.1 \%$ - glucocorticoids, $7.2 \%$ - biological agents and $15.2 \%$ - symptomatic slow-acting drugs in osteoarthritis. At the same time, $68 \%$ of patients needed additional analgesic therapy with nonsteroidal anti-inflammatory drugs (NSAIDs). Slightly less than half of the surveyed patients (46.9\%) noted a moderate effect of analgesic therapy, $22.7 \%$ - a low effect and 5\% - no effect, $23.7 \%$ rated the effectiveness of therapy as good and only $1.7 \%$ - as excellent. At the same time, only $15.6 \%$ of patients were completely satisfied with the result of NSAIDs, $64 \%$ were partially satisfied with the treatment and $20.4 \%$ were completely dissatisfied. As the reason of insufficient effectiveness of NSAIDs, most often (34.3\%) patients named fear of adverse events associated with taking drugs, 19.4\% - weak drugs, $15.3 \%$ - insufficient attention of doctors to complaints, $6.6 \%$ - poor diagnosis of the causes of pain. Others found it difficult to answer or were completely satisfied with the treatment. $40 \%$ of patients used additional methods, most often chiropractic $(12.3 \%)$, acupuncture $(4.8 \%)$, physiotherapy $(12.7 \%)$ and folk remedies $(7.4 \%)$.

Conclusion: A significant proportion of patients with RD don't have adequate pain control. Only $25.4 \%$ of patients rate the result of treatment as good and excellent, and even fewer patients (15.6\%) are completely satisfied with the results of therapy. Thus, a personalized approach to analgesic therapy is necessary, taking into account the expectations of patients regarding the results of treatment.

Disclosure of Interests: None declared

DOI: 10.1136/annrheumdis-2021-eular.2806

\section{AB0268 \\ LOW DOSE TACROLIMUS IS AN EFFECTIVE ADD ON THERAPY FOR PATIENTS WITH ACTIVE RHEUMATOID ARTHRITIS - A SINGLE CENTRE EXPERIENCE}

N. Prabu ${ }^{1}$, V. Petciappan ${ }^{2}$, G. Anand ${ }^{1}$, T. A ${ }^{3}$, A. Nijish ${ }^{3} .{ }^{1}$ Sakthi Rheumatology Centre Pvt. Ltd, Rheumatology, Coimbatore, India; ${ }^{2}$ PSG Institute of Medical
Sciences \& Research, General Medicine, Coimbatore, India; ${ }^{3}$ PSG College of Pharmacy, Pharmacy Practice, Coimbatore, India

Background: Rheumatoid arthritis (RA) a chronic inflammatory arthritis requiring tight control of disease activity. While traditional DMARDS have been used effectively, there always remains a need for add on drugs in good number of patients. Tacrolimus since its first approval in 2004 had been used widely as monotherapy and in combination with conventional and biologica DMARDS. The primary concern was safety followed by the efficacy for patients with active disease.

Objectives: The main objective was to ascertain the safety and tolerability of patients who were treated with tacrolimus as an add on therapy over and above the standard care in RA.

Methods: A retrospective analysis of patients who were prescribed Tacrolimus from January 2019 to August 2020 was done. Details of patients along with the change in Blood pressure(BP), Serum creatinine, Blood suga and Clinical disease activity index(CDAI) before and after tacrolimus were analyzed.

Results: A total of 245 patients with active Rheumatoid arthritis received the drug. The mean age was $48.58(1.49)$ years and the disease duration was $5.9(0.56)$ years. Of 245 patients, 24 patients were lost to follow up,103 patients stopped the drug for various reasons and 118 patients are still continuing the drug. The mean tacrolimus dose was $1.24+0.46 \mathrm{mg}$ in the patients who are continuing. The commonest reason for stopping the drug was adverse events (57\%) followed by lack of efficacy(29\%), low disease activity $(8 \%)$ and others $(7 \%)$. There was no significant change in the mean blood pressure, Blood sugars and Creatinine levels in both the stopped and continuing group. However the CDAl and the steroid dosages reduced significantly in the patients who are still on tacrolimus. The lost to follow up group had high disease activity at baseline and also were on higher doses of steroids.

\begin{tabular}{|c|c|c|c|c|c|c|c|}
\hline \multirow{2}{*}{$\begin{array}{l}\text { PARAM } \\
\text { ETERS }\end{array}$} & \multicolumn{3}{|c|}{ RA - CONTINUING(118) } & \multicolumn{3}{|c|}{ RA STOPPED(103) } & \multirow{2}{*}{$\begin{array}{c}\begin{array}{c}\text { LOST TO } \\
\text { FOLLOWUP } \\
(\mathbf{2 4 )}\end{array} \\
\begin{array}{c}\text { BEFORE } \\
\text { TAC }\end{array}\end{array}$} \\
\hline & $\begin{array}{l}\text { BEFORE } \\
\text { TAC }\end{array}$ & $\begin{array}{c}\text { AFTER } \\
\text { TAC }\end{array}$ & $p$ value & $\begin{array}{c}\text { BEFORE } \\
\text { TAC }\end{array}$ & AFTER TAC & $\begin{array}{c}P \\
\text { value }\end{array}$ & \\
\hline $\begin{array}{l}\text { SBP mm } \\
\text { of hg }\end{array}$ & $100.44(9.54)$ & $101.06(9.80)$ & 0.67 & 103(9.77) & 104(9.92) & 0.44 & $127.35(10.05)$ \\
\hline $\begin{array}{l}\text { DBP mm } \\
\text { of hg }\end{array}$ & $66.30(6.26)$ & 67.22(6.37) & 0.30 & $68.44(6.4)$ & $70.43(6.65)$ & 0.07 & $82.83(5.05)$ \\
\hline SUGAR mg & $76.43(13.73)$ & $76.67(11.24)$ & 0.95 & $71.86(10.79)$ & $76.74(14.1)$ & 0.08 & $89.12(9.7)$ \\
\hline S.CR mg & $0.55(0.06)$ & $0.56(0.09)$ & 0.80 & $0.66(0.16)$ & $0.57(0.06)$ & 0.21 & $0.74(0.06)$ \\
\hline $\begin{array}{l}\text { STEROID } \\
\text { USE mg }\end{array}$ & $2.82(0.41)$ & $1.65(0.54)$ & $<0.001$ & $2.12(0.43)$ & $2.43(0.54)$ & 0.36 & $2.86(1.42)$ \\
\hline CDAI & $12.28(1.84)$ & $7.42(1.49)$ & $<0.001$ & $12.23(2.03)$ & $10.49(2.69)$ & 0.07 & $16.62(3.88)$ \\
\hline
\end{tabular}

Conclusion: Low dose Tacrolimus is an effective add on therapy for patients with high disease activity and did not lead to change in serum creatinine, blood pressure or change in blood sugars in the study subjects.

REFERENCES:

[1] Yocum $D$ et al. Safety of tacrolimus in patients with rheumatoid arthritis: long-term experience. Rheumatology 2004; 43:992-999.

[2] Shouma Dutta, Yasmeen Ahmad. The efficacy and safety of tacrolimus in rheumatoid arthritis. Therapeutic Advances in Musculoskeletal Disease Ther Adv Musculoskel Dis. 2011; 3(6) 283-291.

Disclosure of Interests: None declared

DOI: 10.1136/annrheumdis-2021-eular.2822

\section{$\mathrm{AB} 0269$ \\ ARE INTERFERON-GAMMA RELEASE ASSAYS RELIABLE TO DETECT TUBERCULOSIS INFECTION IN PATIENTS WITH RHEUMATOID ARTHRITIS TREATED WITH JANUS KINASE INHIBITORS?}

C. Castellani ${ }^{1}$, E. Molteni ${ }^{1}$, A. Altobelli ${ }^{1}$, C. Garufi ${ }^{1}$, S. Mancuso ${ }^{1}, \mathrm{~F}$. R. Spinelli ${ }^{1}$, F. Ceccarelli ${ }^{1}$, F. Conti ${ }^{1}$, R. Scrivo ${ }^{1}$. ${ }^{1}$ Sapienza University of Rome, UOC Reumatologia - Dipartimento di Scienze Cliniche Internistiche, Anestesiologiche e Cardiovascolari, Roma, Italy

Background: The therapeutic armamentarium for patients with rheumatoid arthritis (RA) has recently been enriched with the family of Janus kinase (JAK) inhibitors. Because the risk of reactivation of latent tuberculosis infection (LTBI) following the use of these drugs seems to be similar to that seen with anti-TNF agents, screening for $L T B I$ is recommended in patients with RA before starting 